\title{
Response to Gefitinib/Crizotinib Combination in a Pulmonary Sarcomatoid Carcinoma Patient Harboring Concurrent EGFR Mutation and MET Amplification
}

Xiaomeng Wang ${ }^{1}$, Jie $\mathrm{Cao}^{1}$, Shui Cao ${ }^{1}$, Weijiao $\mathrm{Du}^{1}$, and Weihong Zhang ${ }^{1}$

${ }^{1}$ Affiliation not available

March 21, 2021

\begin{abstract}
Pulmonary sarcomatoid carcinoma; non-small cell lung cancer; EGFR mutation; MET amplification; crizotinib/gefitinib
\end{abstract}

Hosted file

Manuscript 1.pdf available at https://authorea.com/users/402920/articles/514633-responseto-gefitinib-crizotinib-combination-in-a-pulmonary-sarcomatoid-carcinoma-patientharboring-concurrent-egfr-mutation-and-met-amplification 